${ }^{1}$ Department of Health Sciences and Child Dentistry, Piracicaba Dental School, University of Campinas (UNICAMP), Piracicaba, São Paulo, Brazil.

${ }^{2}$ Department of Community Health Jundiai Medical School Jundiaí, São Paulo, Brazil.

${ }^{3}$ Department of Physiatry and Nursing, Faculty of Health Sciences, University of Zaragoza, Spain.
*Corresponding author:

Maria da Luz Rosário de Sousa Av Limeira 901 Piracicaba, São Paulo, Brazil

Email: luzsousa@unicamp.br

Received for publication: October 9 , 2020

Accepted: December 21, 2020

\section{Effects of the intervention of the Multicenter Study IDEFICS on the prevalence of caries in Spanish children}

\author{
Vinícius Aguiar Lages ${ }^{1}$ (iD, Maria Paula Rando \\ Meirelles $^{1}$ (iD) Marília Jesus Batista ${ }^{2}$ (iD Carolina \\ Matteussi Lino ${ }^{1}$ (iD) Andréa Moscardini da Costa ${ }^{1}$ (iD \\ Luis Alberto Moreno Aznar ${ }^{3}$ (iD) Maria da Luz Rosário \\ de Sousa $a^{1, *}$ iD
}

Aim: To evaluate the effects of an intervention for the prevention of obesity on the prevalence of dental caries disease in Spanish children. Methods: Two cities participated intervention study nested in a cohort IDEFICS (Identification and prevention of dietary and lifestyle induced health effects in children and infants): Huesca, where there was a 2-year intervention, which encouraged less sugar consumption; and Zaragoza (control). The prevalence of caries was evaluated by examining the 1st permanent molars in the 7-11 age range, using the ICDAS (International Caries Detection and Assessment System). These teeth erupt at 6 years of age and at the baseline (2007-2008) were free of caries because they were not present in the oral cavity. As outcomes, white spots were selected, combining the ICDAS criteria 1 and 2, and untreated caries, combining criteria 4, 5 and 6 . Their association with socioeconomic variables, BMI (Body Mass Index), frequency of sugar intake, sex and parents' perceptions of their children, was investigated. To do so, the chi-square test was applied $(p<0.05)$. Results: The sample consisted of 281 children. The prevalence of white spots and untreated caries was higher in Huesca, despite the intervention. There was no association between the outcomes and the variables studied $(p>0.05)$. Conclusion: The intervention for the prevention of obesity did not exert any association with the prevalence of caries in Spanish children.

Keywords: Oral health. Dental caries. Obesity. 


\section{Introduction}

The prevalence of childhood obesity has increased rapidly in Europe, and in other continents, and has become a serious global public health problem ${ }^{1}$. This problem tends to persist into adult life, and is a risk factor in the occurrence of various chronic diseases, such as cardiovascular disease and diabetes ${ }^{1}$. The fact that eating habits are a key common etiological component of both obesity and dental caries ${ }^{2}$ stimulates interest as the latter is also a serious public health problem in several countries ${ }^{3}$ and the prevalence of both diseases can be reduced with healthy diets and low sugar consumption?

Studies on the relationship between obesity and dental caries present inconclusive results. Some have shown a positive association between them ${ }^{2}$, while others ${ }^{4}$ show no relationship between these factors in schoolchildren, but found that the higher the parents' educational level, the lower the prevalence of obesity and dental caries among their children. Socioeconomic inequalities can create unequal opportunities among people ${ }^{5}$ and have different effects on these diseases, as they are influenced by factors such as education, income and saccharose-rich diets 2,5 .

Thus, new methodologies are necessary to verify this association. Studies of schoolbased interventions ${ }^{6}$ have been effective in improving the health and behavioral conditions of adolescents, considering that the school period is an essential phase for acquiring knowledge, modifying and creating healthier lifestyle habits. Different methods of interventions ${ }^{6}$ have managed to cause positive changes in lifestyle through increased consumption of fruits and vegetables and increased levels of physical activity. However, the scientific literature lacks studies of this type focused on oral health.

To face this growth of obesity in the population, the multicentric IDEFICS (Identification and prevention of dietary- and lifestyle-induced health effects in children and infants) was set up, with intervention modules which addressed diet, physical activity, and stress management ${ }^{7}$.

It was a prospective cohort study in a large diverse sample of children in Europe, which started at the beginning in 2007. It investigated the causes of dietary and lifestyle-related diseases and disorders, with a main focus on overweight and obesity ${ }^{8}$. This cohort involved the drawing up, implementation and assessment of a community-oriented intervention program for the primary prevention of obesity in a controlled study project ${ }^{7}$. Spain was the focus of this study and it took place in the cities of Zaragoza and Huesca.

The I.FAMILY study, which continued from the IDEFICS, verified determinants of eating behavior in children, adolescents and their parents of European origin ${ }^{9}$. Based on data collected from more than 10,000 children who were under 10 years old in the IDEFICS study, the I.FAMILY reevaluated these children and their families and identified those who maintained healthy diets and eating habits from the intervention program and compared them to children who had not received the intervention?. This phase, which began in 2013, included the oral health assessment of Spanish children participating, thereby providing a pioneering Dentistry study within a cohort with a focus on behaviors, lifestyles and eating habits. The purpose of this study was to evaluate the effects of an intervention for the prevention of obesity on the prevalence of dental caries disease in Spanish children. 


\section{Materials and Methods}

\section{The IDEFICS and IFAMILY studies}

A cohort of 16224 children between 2 to 9-year-olds from eight European countries (Sweden, Germany, Hungary, Italy, Cyprus, Spain, Belgium and Estonia) participated in the first population survey of the IDEFICS study. Defined as T0, it took place between September 2007 and May 2008 was the first stage (baseline) of the prospective cohort study and was the initial stage for the IDEFICS intervention (Figure A). All children in the defined age group residing in the regions studied and attending public primary schools (grades 1 and 2), preschools or kindergartens were eligible to participate. In addition to the signed informed consent provided by parents, each child was invited to give their verbal approval. The T0 exams included anthropometric data, lifestyle, biological markers, behavioral and sociodemographic characteristics and were based on a highly standardized protocol, as set out by Ahrens et al. ${ }^{8}$ (2011).

The IDEFICS study was not designed with population representativeness of each country. In most countries, the regions selected were individual cities or communities, most of which were located in the same geographical area. The intervention and control regions in each country were selected for convenience, such as the distance between the research teams involved, in order to reduce costs. The T0 occurred in the intervention (where education actions would be carried out) and control (without health education actions) regions selected in these countries, allowing researchers to assess and describe health conditions, eating habits and lifestyle of children in Europe, taking regional, social, biological and sex aspects into account.

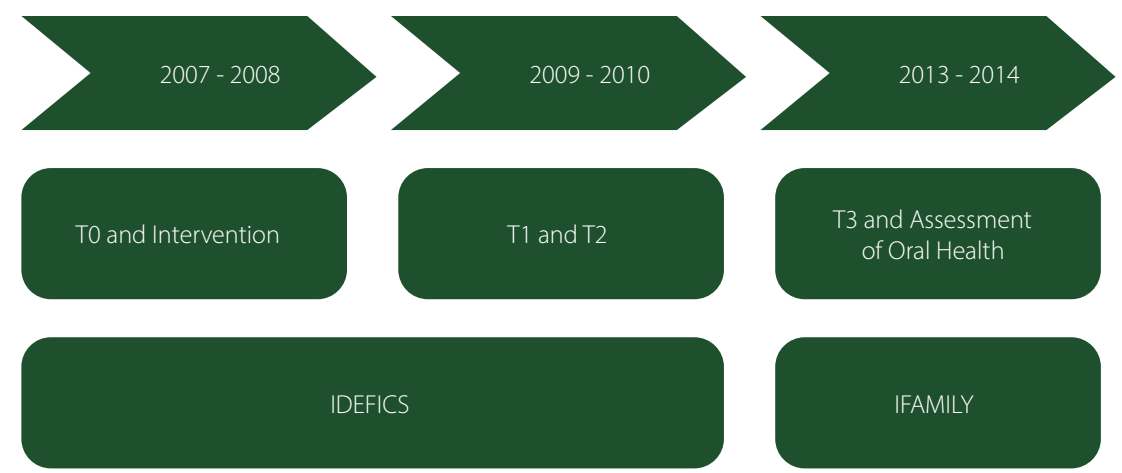

Figure A. Schedule of exams of the IDEFICS cohort and the IFAMILY study. T0, Initial research phase (baseline); T1, first exam after intervention; T2, questionnaires sent to participants via postal service to assess the intervention; T3, second exam after intervention, with assessment of oral health in Spain.

After this phase, the primary prevention program was implemented. The intervention was designed to address key behaviors in relation to obesity (diet, physical activity and stress) at four levels: individual (children), family (parents), school and community. At these levels, six messages related to these behaviors were worked on, through 10 separate modules with intervention measures targeting each level. The six messages were "increase water consumption"; "increase consumption of fruit and vegetables"; "reduce daily screen time (television and computer)"; "increase daily physical activity"; "improve the quality of family life"; "ensure adequate sleeping hours". The interven- 
tion design and details of the different intervention modules of the IDEFICS study are described, according to their level of intervention 7,10 .

The effects of the intervention were evaluated during the T1, 2 years after T0, repeating the same exam modules with children from both control and intervention areas, to compare both regions of each country. At the end of $T 1,69 \%(n=11,189)$ of the children who had participated were reevaluated. Dropout between the exams was higher among those with overweight, low schooling, children of single parents and low scores for well-being ${ }^{11}$. The prevalence of overweight and obesity stratified by sex and country were recorded. In 2010, a second follow-up, defined as T2, was conducted using a questionnaire sent through the postal service to all intervention participants to evaluate sustainability of behavioral change.

As a starting point for the I.FAMILY study described in Ahrens et al. ${ }^{9}$ (2017), another follow-up exam (T3) was carried out between 2013 and 2014, when those children had 7 to 15-year-olds, with an almost equal proportion of boys and girls. This stage included an assessment of the oral health conditions of the children who had participated in the study in Spain, the only country where this initiative occurred. As the aim was to investigate entire families, all siblings in the same age range as these children were invited. The role of family characteristics, family structure and family life in relation to child development is one of the focuses of I.FAMILY9, in which at least one parent of each index child participated and provided information about their family. In Spain, it is estimated that 1,591 children participated in the baseline and 445 of these had their oral health assessed in T3, 281 (59.2\%) aged from seven to 11 and 194 (40.8\%) from 12 to 15 years.

This study was approved by the Ethics Committee (protocol P113/2012 - Spain). No child underwent any procedure without their parents' prior consent for exam, sample collection, subsequent analysis and storage of personal data and samples collected.

\section{Population and study design}

The present study included 281 children from the Spanish cohort in the IDEFICS study, participating from baseline (TO) and aged from 7 to 11 in T3 (I.FAMILY), when they participated in the oral health assessment. The Spanish city of Zaragoza was selected as a control and the intervention occurred in Huesca.

The aim of the dietary intervention, considered the most important for this study because of the common risk factor for caries and obesity, set out to improve the children's eating habits, by increasing their daily consumption of water, fruit and vegetables $^{7,10}$ and, thus reduce their intake of sugars. There was no intervention in oral hygiene habits, such as frequency of brushing or use of dental floss, for example.

Data on sex frequency of sugar intake and children's anthropometrics were obtained at T0. From the questionnaires applied to parents also at T0, information on family income and parents' levels of education were collected. Another questionnaire answered by parents at T3 described their perception of their children's weight. Assessment of oral health occurred only at T3.

\section{Frequency of sugar intake}

The frequency of sugar intake was estimated using a suitable appropriately reproduced $^{12}$ and validated ${ }^{13}$ Children's Eating Habits Questionnaire (CEHQ). This tool 
investigated the frequency of food consumption and behavior associated with overweight, obesity and children's general health. The CEHQ includes a Food Frequency section (FFQ) in which parents or other caregivers living with the child reported the frequency of their child's consumption of sugar foods over a typical week in the previous 4 weeks. This allowed for the reduction of likelihood of a "special week", for example due to holidays or illness. Consequently, week-to-week variability was reduced. To facilitate completion of the questionnaire, the same response scale was used for all dietary items of the CEHQ-FFQ. The response options were as follows: Never/less than once a week, 1-3 times a week, 4-6 times a week, 1 time a day, 2 times a day, 3 times a day, 4 or more times a day, and No idea. This scale was adopted using the eating habits questionnaire of the Early Childhood Longitudinal Survey of the United States Department of Agriculture ${ }^{14}$ as a basis. Intake frequencies were evaluated without trying to quantify portion sizes. For the present study, this variable was divided into "Up to 3 times a day" and "4 or more times a day", as a sugar consumption frequency greater than 4 times a day is directly related to the development of caries disease ${ }^{15}$.

\section{Anthropometry}

The children's weight was measured by Tanita BC 420 SMA scale (TANITA Europe $\mathrm{GmbH}$, Sindelfingen, Germany) while their height was measured using a SECA 225 stadiometer (SECA GmbH \& Co. KG., Hamburg, Germany). The measurements were taken in the morning, with the children in fasting and wearing underwear only. Body Mass Index (BMI) was calculated according to the International Obesity Task Force $(\text { IOTF })^{16}$, where low weight $=$ BMl $<17 \mathrm{~kg} / \mathrm{m}^{2}$, normal weight $=17 \mathrm{~kg} / \mathrm{m}^{2} \leq \mathrm{BMl}<25 \mathrm{Kg} / \mathrm{m}^{2}$, overweight $=25 \mathrm{Kg} / \mathrm{m}^{2} \leq \mathrm{BMl}<30 \mathrm{Kg} / \mathrm{m}^{2}$ and obesity $=\mathrm{BMI} \geq 30 \mathrm{Kg} / \mathrm{m}^{2}$.

\section{Questionnaire applied to parents}

Parents answered questionnaires on the socioeconomic data of the family and their perceptions of their children's body weight ${ }^{12}$. Data on the parents' education levels were based on the International Standard Classification of Education (ISCED) ${ }^{17}$, which levels 0-2 are classified as low, while levels 3-4 are medium and 5-6 are high levels of education. We have summed low and medium categories, versus high level of education. Family income was evaluated by the question "What is your monthly family income?" using specific Spanish categories based on people's average net income ${ }^{18}$. The answers were grouped into low to medium or high incomes. Parents' perceptions of their child's weight were classified as "underweight, adequate or overweight".

\section{Oral Health Assessment}

The selection of the sample for the assessment of oral health was performed based on the absence/presence of the first molar in the baseline period (T0). As the first molars erupt around the 6 years old, in the baseline these teeth were free of caries, as they were not in the oral cavity. As no oral health assessment was performed previously, we opted to exclude children who, in the T0, had the first molar erupted, remaining in the sample only children from 7 to 11 years old who presented the eruption of these teeth after baseline (TO). The children's oral health was assessed at T3 on the basis of exams for the prevalence of dental caries and periodontal disease, and observation of the amount of accu- 
mulated bacterial plaque in the first permanent molars (teeth 16, 26, 36 and 46). For all of these exams, a dental diagnostic plane mouth mirror $\mathrm{N}^{0} 5$ and a spherical calibrated periodontal probe were used, under artificial light, with both examiner and child seated.

Caries disease was evaluated by the International Caries Detection and Assessment System (ICDAS) ${ }^{19}$, which combines the use of visual and tactile signs of caries lesions and allows for detection of the disease in its early stages. The examination was performed after prophylaxis, relative isolation and drying of the teeth with a portable air jet. The clinical stages of the caries lesions were established according to the histological classification proposed by Ekstrand et al. ${ }^{20}$ (1995), ranging from the identification of a white spot on a dental surface, which could need drying to be visualized (code 1) or not (code 2), lesions on dental enamel (code 3), to a cavity visible in dentin (codes 4, 5 and 6 ). Codes 1 and 2 were considered for white spots, and codes 4, 5 and 6 were used for untreated caries, and these lesions were summed up for each outcome.

The existence of periodontal disease was evaluated by the Community Periodontal Index (CPI), according to the methodology recommended by the World Health Organization $(\mathrm{WHO})^{21}$ for epidemiological surveys in oral health. The codes are 0 - Healthy sextant, 1 - Gingival bleeding, 2 - Dental calculus, 3 - Shallow periodontal pocket, between 3.5 and $5.5 \mathrm{~mm}$, and 4 - Deep periodontal pocket, greater than $5.5 \mathrm{~mm}$. The amount of plaque was observed according to the Plaque Index (PI) proposed by Silness and Loe 22 (1964), by means of the following codes: 0 - Absence of biofilm, 1 Tooth clean with biofilm detectable only with probe, 2 - Moderate deposit of biofilm visible to the naked eye, and 3 - Large accumulation of biofilm filling the entire gingival margin. Data on periodontal conditions were analyzed in a descriptive manner, with the prevalence of periodontal disease by sextant, with a view to describing the oral health of the patients, without any relation to the outcomes used.

Examiner calibration was carried out through theoretical discussions and practical activities, simulating the different conditions and situations that the professionals would encounter during the practical work. The examiners were calibrated for ICDAS caries criteria with a standard examiner, who also assisted in data collection First, they did an on-line calibration (https://www.icdas.org/icdas-e-learning-course), and then an exercise with 20 children. The Kappa values weighted for inter-examiner and intra-examiner agreement exceeded 0.85 for the ICDAS and CPI indices.

\section{Statistical analysis}

Descriptive statistics were used to define sociodemographic and oral health characteristics. Pearson's Chi-square test was used to compare categorical variables (gender, educational level, income, frequency of sugar intake and BMI, with dental caries and white spots as outcomes). Data were analyzed using IBM SPSS Statistics, Version 20. The significance level was set at 0.05 .

\section{Results}

The socioeconomic characterization of the T3 sample was similar to that at the baseline. There was a slight reduction in the percentage of low-income children and an increase in the number of middle-income children in both cities (Table 1). 
Table 1. Socioeconomic data of the total sample at T0 (2007) and of the sample of 7 to 11-year-olds at T3 (2013), per Spanish city.

\begin{tabular}{|c|c|c|c|}
\hline Variable per city & & TO & T3 \\
\hline Total sample & & $\mathrm{N}=1,509(100.0 \%)$ & $\mathrm{N}=281(100.0 \%)$ \\
\hline \multicolumn{4}{|l|}{ Zaragoza (control) } \\
\hline Sample & & $\mathrm{N}=799(52.9 \%)$ & $\mathrm{N}=175(62.3 \%)$ \\
\hline \multirow{4}{*}{$\begin{array}{l}\text { Level of } \\
\text { education }\end{array}$} & Low & $76(9.77 \%)$ & $6(5.6 \%)$ \\
\hline & Medium & $281(36.1 \%)$ & $40(37.4 \%)$ \\
\hline & High & $421(54.11 \%)$ & $61(57.0 \%)$ \\
\hline & Total & $778(100.0 \%)$ & $107(100.0 \%)$ \\
\hline \multirow{4}{*}{ Family income } & Low & $125(17.0 \%)$ & $9(7.4 \%)$ \\
\hline & Medium & 409 (55.95\%) & $76(62.8 \%)$ \\
\hline & High & $197(26.94 \%)$ & $36(29.8 \%)$ \\
\hline & Total & $731(100.0 \%)$ & $121(100.0 \%)$ \\
\hline \multicolumn{4}{|c|}{ Huesca (intervention) } \\
\hline Sample & & $\mathrm{N}=710(47.1 \%)$ & $\mathrm{N}=106(37.7 \%)$ \\
\hline \multirow{4}{*}{$\begin{array}{l}\text { Level of } \\
\text { education }\end{array}$} & Low & $39(5.55 \%)$ & $3(4.1 \%)$ \\
\hline & Medium & $316(45.0 \%)$ & $39(53.4 \%)$ \\
\hline & High & $347(49.4 \%)$ & $31(42.5 \%)$ \\
\hline & Total & $702(100.0 \%)$ & $73(100.0 \%)$ \\
\hline \multirow{4}{*}{ Family income } & Low & $84(13.0 \%)$ & $3(4.1 \%)$ \\
\hline & Medium & $457(70.96 \%)$ & $59(78.6 \%)$ \\
\hline & High & $103(16.0 \%)$ & $13(17.3 \%)$ \\
\hline & Total & $644(100.0 \%)$ & $75(100.0 \%)$ \\
\hline
\end{tabular}

Note: Between TO and T3, the variables were not significant and, therefore, the characteristics of the sample remained the same.

The prevalence of children with dentin carious lesions ( $p=0.015)$ and with white spots $(p=0.016)$ in the first molars was higher in Huesca, despite the intervention (Figure B).

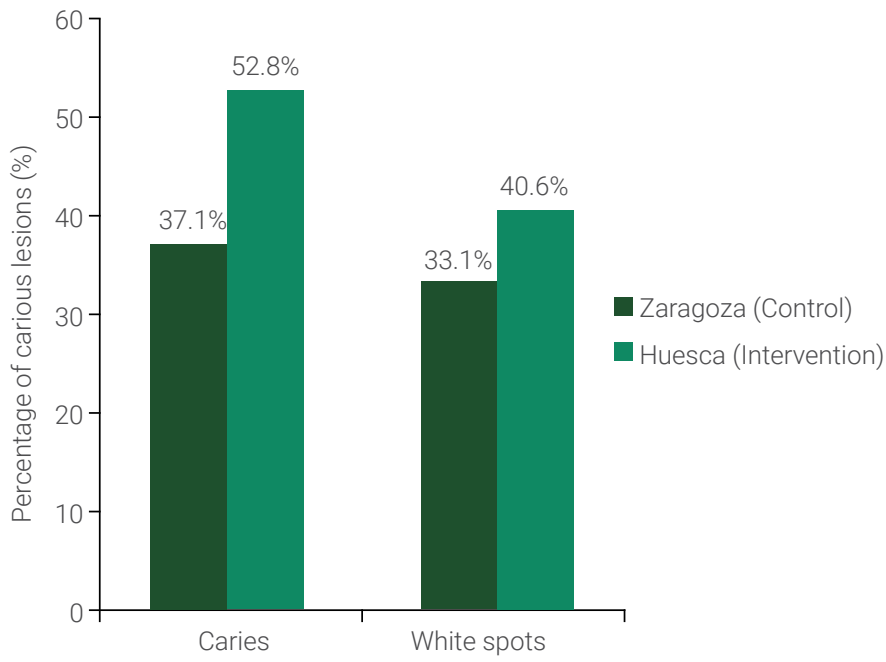

Figure B. Prevalence of caries and white spots assessed in the first permanent molars of 7 to 11 -yearolds in the post-intervention period (T3), in Zaragoza and Huesca, Spain, 2013-2014. 
The analysis of first molars with carious lesions in Zaragoza shows that $54.2 \%$ of them were at the initial caries stage, while in Huesca this rises to $59.6 \%$. The Zaragoza children presented a lower percentage of visible plaque, but presented a higher percentage of sextants with bleeding. In Huesca, there were more children with localized visible plaque and plaque in the whole gingival margin, and although they presented a lower percentage of sextants with bleeding, $5 \%$ presented calculus, a more serious condition (Table 2).

Table 2. Oral health data for 7 to 11-year-olds per city, at T3, in terms of the I.FAMILY study, Spain, 2013

\begin{tabular}{lcccc}
\hline \multirow{2}{*}{ Oral Health data } & \multicolumn{2}{c}{ Zaragoza (Control) } & Huesca (Intervention) \\
\cline { 2 - 5 } & $\mathbf{n}$ & $\%$ & $\mathbf{n}$ & $\%$ \\
\hline First molars with carious lesions (ICDAS) & & & & \\
\hline White spots after drying & 49 & 32.8 & 33 & 28.9 \\
\hline White spots without drying & 21 & 14.0 & 18 & 15.8 \\
\hline Enamel cavitation & 11 & 7.4 & 17 & 14.9 \\
\hline Darkened dentin without visible cavitation in enamel & 7 & 4.7 & 2 & 1.38 \\
\hline Dentin cavitation less than $1 / 2$ the surface & 3 & 2.0 & 1 & 0.9 \\
\hline Dentin cavitation more than $1 / 2$ the surface & 58 & 38.9 & 43 & 37.7 \\
\hline Total & 149 & 100.0 & 114 & 100.0 \\
\hline Bacterial Plaque Index (Silness PI) & & & & \\
\hline No plaque & 54 & 30.85 & 23 & 21.69 \\
\hline Plaque visible with probe & 68 & 38.85 & 41 & 38.67 \\
\hline Localized plaque visible & 24 & 13.7 & 21 & 19.81 \\
\hline Plaque visible in whole gengival margin & 29 & 16.57 & 20 & 18.86 \\
\hline Total & 175 & 100.0 & 106 & 100.0 \\
\hline Periodonal condition per sextant examined (CPI) & & & & \\
\hline Healthy & 643 & 65.88 & 419 & 69.6 \\
\hline Bleeding & 319 & 32.68 & 152 & 25.25 \\
\hline Calculus & 14 & 1.43 & 31 & 5.14 \\
\hline Total & 976 & 100.0 & 602 & 100.0 \\
\hline
\end{tabular}

There was no association between caries and white spot disease with the socioeconomic, sex, parents' perception of their children's weight, sugar consumption or body weight variables in any of the cities. The results of parents' perception of their children's weight showed responses which were inconsistent with their children's actual weight for those considered underweight, despite having normal weight (Tables 3 and 4).

Table 3. Bivariate analysis for 7 to 11-year-olds per city in the IDEFICS study in Spain, for untreated caries

\begin{tabular}{|c|c|c|c|c|c|c|c|c|}
\hline \multirow{3}{*}{ Variables } & \multicolumn{8}{|c|}{ Untreated caries } \\
\hline & \multicolumn{4}{|c|}{ Huesca (Intervention) } & \multicolumn{4}{|c|}{ Zaragoza (Control) } \\
\hline & No & Yes & Total & $\mathrm{p}$ value & No & Yes & Total & $p$ value \\
\hline \multicolumn{9}{|l|}{ Leval of education } \\
\hline High & $16(51.6 \%)$ & $15(48.4 \%)$ & $31(100.0 \%)$ & \multirow{2}{*}{0.459} & $36(59.0 \%)$ & $25(41.0 \%)$ & $61(100.0 \%)$ & \multirow{2}{*}{0.514} \\
\hline Medium-Low & $18(42.9 \%)$ & $24(57.1 \%)$ & $41(100.0 \%)$ & & $30(65.2 \%)$ & $16(34.8 \%)$ & $46(100.0 \%)$ & \\
\hline \multicolumn{9}{|l|}{ Family income } \\
\hline High & $7(53.9 \%)$ & $6(46.1 \%)$ & $13(100.0 \%)$ & \multirow{2}{*}{0.432} & $21(58.3 \%)$ & $15(41.7 \%)$ & $36(100.0 \%)$ & \multirow{2}{*}{0.590} \\
\hline Medium_Low & $26(41.9 \%)$ & $36(58.1 \%)$ & $62(100.0 \%)$ & & $54(63.5 \%)$ & $31(36.4 \%)$ & 85 (100.0\%) & \\
\hline
\end{tabular}


Continuation

\begin{tabular}{|c|c|c|c|c|c|c|c|c|}
\hline \multicolumn{9}{|c|}{ Frequency of sugar intake } \\
\hline $\begin{array}{l}\text { Up to } 3 \text { times } \\
\text { a day }\end{array}$ & $9(47.3 \%)$ & $10(52.6 \%)$ & $19(100.0 \%)$ & \multirow{2}{*}{0.305} & $25(64.1 \%)$ & $14(35.9 \%)$ & $39(100.0 \%)$ & \multirow{2}{*}{0.167} \\
\hline $\begin{array}{l}4 \text { or more } \\
\text { times a day }\end{array}$ & $1(100.0 \%)$ & $0(0.0 \%)$ & $1(100.0 \%)$ & & $5(41.7 \%)$ & $7(58.3 \%)$ & $12(100 . \%)$ & \\
\hline \multicolumn{9}{|l|}{ BMI } \\
\hline Underweight & $1(25.0 \%)$ & $3(75.0 \%)$ & $4(100.0 \%)$ & \multirow{3}{*}{$0.620^{*}$} & $4(80.0 \%)$ & $1(20.0 \%)$ & $5(100.0 \%)$ & \multirow{3}{*}{$0.990^{*}$} \\
\hline Normal & $37(47.4 \%)$ & $41(52.6 \%)$ & $78(100.0 \%)$ & & $72(59.0 \%)$ & $50(41.0 \%$ & $122(100.0 \%)$ & \\
\hline Overweight & $0(0.0 \%)$ & $0(0.0 \%)$ & $0(0.0 \%)$ & & $1(50.0 \%)$ & $1(50.0 \%)$ & $2(100.0 \%)$ & \\
\hline \multicolumn{9}{|c|}{ Parents' perception of their children's weight } \\
\hline Underweight & $9(37.5 \%)$ & $15(62.5 \%)$ & $24(100.0 \%)$ & \multirow{3}{*}{$0.353^{*}$} & $14(45.1 \%)$ & $17(54.9 \%)$ & $31(100.0 \%)$ & \multirow{3}{*}{$0.099 *$} \\
\hline Adequate & $28(51.0 \%)$ & $27(49.0 \%)$ & $55(100.0 \%)$ & & $62(66.7 \%)$ & $31(33.3 \%)$ & $93(100.0 \%)$ & \\
\hline Overweight & $0(0.0 \%)$ & 1(100.0\%) & $1(100.0 \%)$ & & $1(50.0 \%)$ & $1(50.0 \%)$ & $2(100.0 \%)$ & \\
\hline \multicolumn{9}{|l|}{ Sex } \\
\hline Boys & $27(53.0 \%)$ & $24(47.0 \%)$ & $51(100.0 \%)$ & \multirow{2}{*}{0.252} & $52(66.7 \%)$ & $26(33.3 \%)$ & 78 (100.0\%) & \multirow{2}{*}{0.350} \\
\hline Girls & $23(41.8 \%)$ & $32(58.2 \%)$ & $55(100.0 \%)$ & & $58(59.8 \%)$ & $39(40.2 \%)$ & 97 (100.0\%) & \\
\hline
\end{tabular}

Nota: *Fisher's Exact Test

Table 4. Bivariate analysis for 7 to 11-year-olds per city in the IDEFICS study in Spain, for white spots

\begin{tabular}{|c|c|c|c|c|c|c|c|c|}
\hline \multirow{3}{*}{ Variables } & \multicolumn{8}{|c|}{ White spots } \\
\hline & \multicolumn{4}{|c|}{ Huesca (Intervention) } & \multicolumn{4}{|c|}{ Zaragoza (Control) } \\
\hline & No & Yes & Total & $\mathrm{p}$ value & No & Yes & Total & $\mathrm{p}$ value \\
\hline \multicolumn{9}{|l|}{ Leval of education } \\
\hline High & $19(61.3 \%)$ & $12(38.7 \%)$ & $31(100.0 \%)$ & \multirow{2}{*}{0.722} & $39(64.0 \%)$ & $22(36.0 \%)$ & 61(100.0\%) & \multirow{2}{*}{0.542} \\
\hline Medium-Low & $24(57.1 \%)$ & $18(42.9 \%)$ & $42(100.0 \%)$ & & $32(69.6 \%)$ & $14(30.4 \%)$ & $46(100.0 \%)$ & \\
\hline \multicolumn{9}{|l|}{ Family income } \\
\hline High & $9(69.2 \%)$ & $4(30.8 \%)$ & $13(100.0 \%)$ & \multirow{2}{*}{0.395} & $23(63.9 \%)$ & $13(36.1 \%)$ & $36(100.0 \%)$ & \multirow{2}{*}{0.676} \\
\hline Medium-Low & $35(56.5 \%)$ & $26(43.5 \%)$ & $62(100.0 \%)$ & & $58(68.2 \%)$ & $27(31.8 \%)$ & $85(100.0 \%)$ & \\
\hline \multicolumn{9}{|c|}{ Frequency of sugar intake } \\
\hline $\begin{array}{l}\text { Up to } 3 \text { times } \\
\text { a day }\end{array}$ & $15(79.0 \%)$ & $4(21.0 \%)$ & $19(100.0 \%)$ & \multirow{2}{*}{0.608} & $26(66.7 \%)$ & $13(33.3 \%)$ & $39(100.0 \%)$ & \multirow{2}{*}{0.597} \\
\hline $\begin{array}{l}4 \text { or more } \\
\text { times a day }\end{array}$ & $1(100.0 \%)$ & $0(0.0 \%)$ & $1(100.0 \%)$ & & $7(58.3 \%)$ & $5(41.7 \%)$ & $12(100 . \%)$ & \\
\hline \multicolumn{9}{|l|}{ BMI } \\
\hline Underweight & $1(25.0 \%)$ & $3(75.0 \%)$ & $4(100.0 \%)$ & \multirow{3}{*}{$0.297^{*}$} & $4(80.0 \%)$ & $1(20.0 \%)$ & $5(100.0 \%)$ & \multirow{3}{*}{$0.583^{*}$} \\
\hline Normal & $48(61.5 \%)$ & $30(38.5 \%)$ & $78(100.0 \%)$ & & $78(66.1 \%)$ & $40(33.9 \%)$ & $118(100.0 \%)$ & \\
\hline Overweight & $0(0.0 \%)$ & $0(0.0 \%)$ & $0(0.0 \%)$ & & $1(50.0 \%)$ & $1(50.0 \%)$ & $2(100.0 \%)$ & \\
\hline \multicolumn{9}{|c|}{ Parents' perception of their children's weight } \\
\hline Underweight & $15(62.5 \%)$ & $9(37.5 \%)$ & $24(100.0 \%)$ & \multirow{3}{*}{$0.885^{\star}$} & $15(48.4 \%)$ & $16(51.6 \%)$ & $31(100.0 \%)$ & \multirow{3}{*}{$0.266^{*}$} \\
\hline Adequate & $33(60.0 \%)$ & $22(40.0 \%)$ & $55(100.0 \%)$ & & $67(72.0 \%)$ & $26(28.0 \%)$ & $93(100.0 \%)$ & \\
\hline Overweight & $0(0.0 \%)$ & $1(100.0 \%)$ & $1(100.0 \%)$ & & $1(50.0 \%)$ & $1(50.0 \%)$ & $2(100.0 \%)$ & \\
\hline \multicolumn{9}{|l|}{ Sex } \\
\hline Boys & $31(60.8 \%)$ & $20(39.2 \%)$ & $51(100.0 \%)$ & \multirow{2}{*}{0.785} & $53(68.0 \%)$ & $25(32.0 \%)$ & 78 (100.0\%) & \multirow{2}{*}{0.783} \\
\hline Girls & $32(58.2 \%)$ & $23(41.8 \%)$ & $55(100.0 \%)$ & & $64(66.0 \%)$ & $33(34.0 \%)$ & $97(100.0 \%)$ & \\
\hline
\end{tabular}

Nota: * Fisher's Exact Test 


\section{Discussion}

The highlight of this study is the inclusion of oral health assessment in a multicentric European cohort project which investigates chronic diseases with common lifestyle and dietary risk factors such as obesity, diabetes and cardiovascular diseases. Despite the fact that the dental exams took place in Spain only, although eight countries participated in the study, it was innovative, as the IDEFICS was the European multicentric cohort study involving the largest sample of children among studies undertaken to date, none of which included oral health among their analyses, though caries is also diet-related. As it was a longitudinal study, an analysis of the same population in early childhood and, subsequently, their health outcomes in early adolescence, also contributed to the significance of the study. In addition, the diagnosis of caries with the ICDAS index ${ }^{19}$, which considers initial stages of caries, such as white spots and enamel lesions during oral exams, has a great advantage over the Decayed, Missing and Filled Teeth (DMFT) ${ }^{21}$, which only considers cavitations at the dentin level. Among the first molars with carious lesions, more than half were at the initial stage, and would not have been noticed if the DMFT had been used.

The prevalence of untreated caries and white spots were higher in Huesca, despite the intervention. De Bourdeaudhuij et al. ${ }^{23}$ (2015) found that the intervention had no positive effects on diet or lifestyle, such as the consumption of water, soft drinks and fruit juice; fruit and vegetable intake; daily TV viewing time and computer use; and daily levels of physical activity (sports and outdoor games) for the total sample of 2 to 9-year-olds in the eight European countries. Families with lower incomes, a poorer quality of life or were migrants presented the worst results, with lower adherence to the intervention measures ${ }^{11}$. However, we did not find this association in this study.

Possible limitations of the IDEFICS intervention were mentioned: dependence on parents' answering of questionnaires on child behavior; interference from local, regional or national governments in the fight against obesity in the different countries; differences in the penetration of the IDEFICS intervention in each country, given the different cultural contexts, for which there were no adaptations in strategies; and differences in the measure of intervention at child and parent level ${ }^{23}$. It should be emphasized that there was no intervention in oral hygiene behavior in Spain.

There was no association between untreated caries and white spots with body weight. The fact that a child was underweight, of normal weight or overweight/obese did not associated with their oral health or vice versa. This result is in agreement with studies which also did not find this relation with the same age group in the Netherlands, Brazil and Spain ${ }^{4}$, but found a relationship between social determinants and dental caries disease and obesity, such as lower family income and parents' lower educational levels, although this was also not shown in our study. However, Hayden et al. ${ }^{2}$ (2013), in a systematic review study with meta-analysis, argue that there is an association between these diseases, while Dimaisip-Nabuab et al. ${ }^{24}$ (2018) found that underweight children are more likely to experience caries. Through a systematic review of the literature, Hooley et al. ${ }^{25}$ (2012) stated that there is no evidence to suggest that dental caries is associated with either high or low BMI.

Although the exact nature of such associations is not clear, it is possible that there are different factors involved in the development of caries in children with high or low 
BMI or with different socioeconomic profiles. According to Costa et al. ${ }^{4}$ (2013), the conflicting results of the studies could be related to the research design, variations in the environment in which the data were collected, socioeconomic status of the sample, nutritional status measures used, caries assessment indexes used and age differences in the children examined. Nevertheless, it was suggested that combined strategies be implemented simultaneously to control caries and obesity, as they present diet as a common risk factor ${ }^{26}$. The frequency of sugar consumption was not associated with caries and white spots in this study either, but that was probably due to the fact that only 71 parents answered this particular question, of whom only 12 reported consumption more than 4 times a day, as it has already been proven that sugar consumption is directly involved in these diseases ${ }^{3,27}$.

Most interventions in the prevention of obesity and dental caries focus on modifying health behavior. These policies and strategies must be accompanied by other government efforts to improve public education, and deterioration of the state of health and nutrition of the population. Traditional preventive and curative approaches, based solely on education and health care are considered unsustainable and ineffective. Such strategies should target the broader upward flow of social factors which affect sugar consumption. People's decisions to consume sugars is deeply rooted in the social, economic and environmental conditions in which they grow up, live, work and age. Thus, sustainable environments for health promotion should be created so that there is a behavior of commitment to health, where the consumption of sugar is the difficult choice and the consumption of vegetables and fruit is the easy choice in terms of availability and accessibility ${ }^{5,27}$.

Political and economic changes at local, state and national levels could promote and encourage healthier food choices ${ }^{26,27}$. The United Kingdom and Mexico, for example, have successfully passed legislation on drinks containing sugar using successful taxation prototypes adapted from alcohol and tobacco ${ }^{28,29}$. Some experiments already reported suggest that a $20 \%$ tax on sugar-added beverages could reduce the prevalence of caries, obesity, diabetes and other comorbidities, and reduce treatment costs and lead to behavioral changes in food choice ${ }^{29}$. At the same time, sugar-free food, drinks and medicines should not be taxed. Fiscal returns could be used to subsidize the price of vegetables, fruits and sugar-free medicines ${ }^{29}$.

For Grinsberg ${ }^{30}$ (2017), the ideal would be to establish both short- and long-term goals for reducing people's sugar consumption, until the WHO recommended rate of a maximum of $5 \%$ of daily total calorie intake is reached, as the rewards arising out of reduced mortality, morbidity and health expenditures would gradually be enormous, as is happening in Israel. The WHO has recognized that dental diseases are the most common non-communicable diseases worldwide and that the treatment of dental disease is costly. Governments must pressure the food and drug industries, with the backing of appropriate legislation, to reduce the sugar content of their products and offer a wide variety of sugar-free alternatives. Meals provided in schools and other public establishments, such as hospitals, should be sugar free or at least with reduced sugar. All of the aforementioned policies should be supported by initiatives to increase public awareness of the need to reduce the intake of sugary foods and beverages from childhood through life, using national and mother and child nutrition programs ${ }^{27}$. 
All such changes occur amidst the complexities of interactive social, cultural, political, and financial forces which rarely align themselves to promote healthy eating. As in the case of public health efforts to reduce tobacco use, there are keen corporate interests with powerful incentives to oppose or undermine these efforts. This has long been recognized in the case of the tobacco industry and is becoming better recognized in the case of the food and drinks industry ${ }^{30}$.

One limitation to this study was the fact that the oral health exam was undertaken only after the intervention, during T3, which meant it was possible to verify this condition only in the group 7 to 11 years old. Another limitation was that the ICDAS II index was used only in the first permanent molars, which was necessary in the circumstances. For future multicentric cohort studies focusing on diet, obesity and lifestyle, it is suggested that children's oral health be assessed from the baseline, that all teeth be examined, and that macroeconomic policies of wide social reach, such as the taxation of foods rich in sugar and advertising restrictions be included in the intervention measures of the study. Future investigations involving parents' perception of their children's weight would also be important, as a perception incompatible with their children's weight could stimulate diets which lead to weight gain and the development of dental caries.

In conclusion, the intervention for the prevention of obesity in the IDEFICS study did not shown an association with the prevalence of dental caries disease in the children participating in the Spanish cohort.

\section{References}

1. World Health Organization. Global strategy on diet, physical activity and health: childhood overweight and obesity. Geneva: WHO; 2004 [cited 2020 Aug 20]. Available from: https://www.who.int/ dietphysicalactivity/strategy/eb11344/strategy_english_web.pdf.

2. Hayden C, Bowler JO, Chambers S, Freeman R, Humphris G, Richards D, et al. Obesity and dental caries in children: a systematic review and metaanalysis. Community Dent Oral Epidemiol. 2013 Aug;41(4):289-308. doi: 10.1111/cdoe.12014.

3. GBD 2017 Oral Disorders Collaborators, Bernabe E, Marcenes W, Hernandez CR, Bailey J, Abreu LG, et al. Global, Regional, and National Levels and Trends in Burden of Oral Conditions from 1990 to 2017: A Systematic Analysis for the Global Burden of Disease 2017 Study. J Dent Res. 2020 Apr;99(4):362-73. doi: 10.1177/0022034520908533.

4. Costa LR, Daher A, Queiroz MG. Early childhood caries and body mass index in young children from low income families. Int J Environ Res Public Health. 2013 Mar;10(3):867-78. doi: 10.3390/ijerph10030867.

5. Sheiham A, Williams DM. Reducing inequalities in oral health in the Africa and Middle East Region. Adv Dent Res. 2015 Jul;27(1):4-9. doi: 10.1177/0022034515575540

6. Wolf VLW, Samur-San-Martin JE, Sousa SF, Santos HDO, Folmann AG, Ribeiro RR, et al. Effectiveness of obesity intervention programs with based on guidelines for adolescent students: systematic review. Rev Paul Pediatr. 2019;37(1):110-20. doi: 10.1590/1984-0462/;2019;37;1;00015.

7. Verbestel V, De Henauw S, Maes L, Haerens L, Mårild S, Eiben G, et al. Using the intervention mapping protocol to develop a community-based intervention for the prevention of childhood obesity in a multi-centre European project: the IDEFICS intervention. Int J Behav Nutr Phys Act. 2011 Aug;8:82 doi: 10.1186/1479-5868-8-82. 
8. Ahrens W, Bammann K, Siani A, Buchecker K, De Henauw S, lacoviello L, et al. The IDEFICS cohort: design, characteristics and participation in the baseline survey. Int J Obes (Lond). 2011 Apr;35 Suppl 1:S3-15. doi: 10.1038/ijo.2011.30.

9. Ahrens W, Siani A, Adan R, De Henauw S, Eiben G, Gwozdz W, et al. Cohort Profile: The transition from childhood to adolescence in European children-how I.Family extends the IDEFICS cohort. Int J Epidemiol. 2017 Oct 1;46(5):1394-5j. doi: 10.1093/ije/dyw317.

10. Pigeot I, Baranowski T, De Henauw S, IDEFICS Intervention Study Group; IDEFICS Consortium. The IDEFICS intervention trial to prevent childhood obesity: design and study methods. Obes Rev. 2015 Dec;16 Suppl 2:4-15. doi: 10.1111/obr.12345.

11. Hense S, Pohlabeln H, Michels N, Marild S, Lissner L, Kovacs E, et al. Determinants of attrition to follow-up in a multicentre cohort study in children - Results from the IDEFICS study. Epidemiol Res Int. 2013:1-9. doi: 10.1155/2013/936365.

12. Lanfer A, Hebestreit A, Ahrens W, Krogh V, Sieri S, Lissner L, et al. Reproducibility of food consumption frequencies derived from the Children's Eating Habits Questionnaire used in the IDEFICS study. Int J Obes (Lond). 2011 Apr;35 Suppl 1:S61-8. doi: 10.1038/ijo.2011.36.

13. Bel-Serrat S, Mouratidou T, Pala V, Huybrechts I, Börnhorst C, Fernández-Alvira JM, et al. Relative validity of the Children's Eating Habits Questionnaire-food frequency section among young European children: the IDEFICS Study. Public Health Nutr. 2014 Feb;17(2):266-76. doi: 10.1017/ S1368980012005368.

14. ORC Macro. Developing effective wording and format options for a children's nutrition behavior questionnaire for mothers of children in Kindergarten. Report n. 10. Washington: USDA; 2005. doi: 10.22004/ag.econ.291983.

15. Ccahuana-Vásquez RA, Tabchoury CP, Tenuta LM, Del Bel Cury AA, Vale GC, Cury JA. Effect of frequency of sucrose exposure on dental biofilm composition and enamel demineralization in the presence of fluoride. Caries Res. 2007;41(1):9-15. doi: 10.1159/000096100.

16. Cole TJ, Lobstein T. Extended international (IOTF) body mass index cut-offs for thinness, overweight and obesity. Pediat Obes. 2012 Aug;7(4):284-94. doi: 10.1111/j.2047-6310.2012.00064.x.

17. United Nations Educational. Scientific and Cultural Organization. International Standard Classification of Education ISCED 1997. Unesco; 2006. [cited 2020 Sep]. Available from: https://www.cedefop. europa.eu/files/International_Standard_Classification_for_Education_\%28ISCED\%29.pdf.

18. Harrison E, Rose D. The European Socio-economic Classification (ESeC) User Guide. Colchester, UK: University of Essex; 2006.

19. Ismail Al, Sohn W, Tellez M, Amaya A, Sen A, Hasson H, et al. The International Caries Detection and Assessment System (ICDAS): an integrated system for measuring dental caries. Community Dent Oral Epidemiol. 2007 Jun;35(3):170-8. doi: 10.1111/j.1600-0528.2007.00347.x.

20. Ekstrand KR, Kuzmina I, Bjorndal L, Thylstrup A. Relationship between external and histologic features of progressive stages of caries in the occlusal fossa. Caries Res. 1995;29(4):243-50. doi: $10.1159 / 000262076$.

21. Peterse PE, Baez RJ, World Health Organization. Oral health surveys: basic methods, $5 t^{\text {th }}$ ed. Geneva: WHO; 2013 [cited 2020 Sep]. Available from: https://apps.who.int/iris/handle/10665/97035.

22. Silness J, Loe H. Periodontal disease in pregnancy. Correlation between oral hygiene and periodontal condition. Acta Odontol Scand. 1964 Feb;22:121-35. doi: 10.3109/00016356408993968.

23. De Bourdeaudhuij I, Verbestel V, De Henauw S, Maes L, Huybrechts I, Mårild S, et al. Behavioural effects of a community-oriented setting-based intervention for prevention of childhood obesity in eight European countries. Main results from the IDEFICS study. Obes Rev. 2015 Dec;16 Suppl 2:30-40. doi: 10.1111/obr.12347. 
24. Dimaisip-Nabuab J, Duijster D, Benzian H, Heinrich-Weltzien R, Homsavath A, Monse B, et al. Nutritional status, dental caries and tooth eruption in children: a longitudinal study in Cambodia, Indonesia and Lao PDR. BMC Pediatr. 2018 Sep 14;18(1):300. doi: 10.1186/s12887-018-1277-6.

25. Hooley M, Skouteris H, Boganin C, Satur J, Kilpatrick N. Body mass index and dental caries in children and adolescents: a systematic review of literature published 2004 to 2011 . Syst Rev. 2012 Nov 21;1:57. doi: 10.1186/2046-4053-1-57.

26. Joury E, Al-Kaabi R, Tappuni AR. Constructing public health policies in post crisis countries: lessons to learn from the associations between free-sugars consumption and diabetes, obesity and dental caries before, during and after sanctions in Iraq. Z Gesundh Wiss. 2016;24(6):563-9. doi: 10.1007/ s10389-016-0745-4.

27. Sheiham A, James WP. Diet and dental caries: the pivotal role of free sugars reemphasized. J Dent Res. 2015 Oct;94(10):1341-7. doi: 10.1177/0022034515590377.

28. Briggs ADM, Mytton OT, Kehlbacher A, Tiffin R, Elhussein A, Rayner M, et al. Health impact assessment of the UK soft drinks industry levy: a comparative risk assessment modelling study. Lancet Public Health. 2016 Dec 16;2(1):e15-e22. doi: 10.1016/S2468-2667(16)30037-8.

29. Andreyeva T, Long MW, Brownell KD. The impact of food prices on consumption: a systematic review of research on the price elasticity of demand for food. Am J Public Health. 2010 Feb;100(2):216-22. doi: 10.2105/AJPH.2008.151415.

30. Ginsberg GM. Mortality, hospital days and treatment costs of current and reduced sugar consumption in Israel. Isr J Health Policy Res. 2017 Jan 10;6:1. doi: 10.1186/s13584-016-0129-9. 